\title{
Multi-Physics Design of a V-shape IPM Motor
}

\author{
P. Akiki, M. Hage Hassan, M. Bensetti, Ph. Dessante, J-C. Vannier, D. Prieto, M. McClelland
}

\begin{abstract}
In this paper a multi-physics model is proposed for a multi-V-shape Interior Permanent Magnet (IPM) motor with concentrated winding. This work develops a non-linear magnetic model that computes the flux density in the motor. The analytical model includes several novel aspects: it takes into account the local saturation near the iron bridges, it proposes a method for modeling the concentrated tooth winding, it calculates the slot tangential leakage flux and includes it in the flux linkage calculation. The magnetic model is coupled with an electrical model that computes the power factor and the voltage at the motor terminals. A loss model is developed in order to calculate the copper and the iron losses. They are used as inputs to a nodal thermal model that introduces a thermal circuit for concentrated end-winding and computes the temperature of the motor. A mechanical model is developed. It evaluates the mechanical constraints encountered by the structure. The models are verified using finite element computations and numerical calculations performed with dedicated software. Besides, the coupled analytical model is experimentally validated using a prototype motor. Finally, two multi-physics bi-objective optimizations are carried out in order to design the motor for high torque and low speed application.
\end{abstract}

Index Terms-- Concentrated winding, Electrical machines, IPM motor, Multi-physics model, V-shape magnets, Optimization

\section{INTRODUCTION}

$\mathrm{D}$ irect drive motors gained great attention recently not only in the field of electrical vehicles but also in high torque and low speed applications. The low reliability of the conventional geared systems led researchers to investigate direct drive motors with high torque density. Permanent magnet motors with rare earth magnets provided a very good alternative and have been widely studied during the last decades [1]. But, these magnets reached high prices which led manufacturers to study new topologies that avoid or reduce the use of rare-earth materials [2]-[5]. The previously studied structures were generally designed with conventional distributed winding. However, novel doubly salient topologies with multi-V shape interior permanent magnets and concentrated tooth winding were recently studied and the results showed that they are capable of developing a high torque at low rotational speed [6]. Besides, the concentrated

Paul Akiki, Maya Hage Hassan, Jean-Claude Vannier and Mohamed Bensetti are with GeePs | Group of electrical engineering-Paris, UMR CNRS 8507, CentraleSupélec, Univ.Paris-Sud, Université Paris-Saclay, Sorbonne Universités, UPMC Univ Paris 06, 3 \& 11 rue Joliot-Curie, Plateau de Moulon 91192 Gif-sur-Yvette, France. (emails: paul.akiki@centralesupelec.fr, maya.hagehassan@centralesupelec.fr,philippe.dessante @centralesupelec.fr, jean-claude.vannier@centralesupelec.fr, mohamed.bensetti@centralesupelec.fr)

Dany Prieto and Mike McClelland are with Leroy Somer Motor, 16000 Angoulême, France. (e-mails: dany.prieto@mail.nidec.com, mike.mcclelland@mail.nidec.com) winding reduces the length of the end-winding which decreases the copper losses and may improve the efficiency.

In literature, the magnetic model of motors with concentrated tooth winding is generally presented with linear assumptions. The saturation of the ferromagnetic material is not considered in all parts of the motor [7]-[9]. Besides, when including the losses in the structure, the rotor iron losses are generally neglected [10]. As for the mechanical stresses, they are either calculated using simplified equations [11], or analyzed using finite element models [12], [13].

In this paper, we propose to develop an improved multiphysics model of a concentrated winding motor having 18 slots and 16 poles with two V-shape barriers per pole filled with ferrite magnets (Fig. 1). The main non-linear magnetic model includes several novel aspects: it takes into account the local saturation near the iron bridges, it proposes a method for modeling the concentrated tooth winding, it calculates the slot tangential leakage flux and includes it in the winding flux linkage calculation. The developed analytical model accurately computes the performances of the motor while being 5 times faster than finite element models. An electric equivalent circuit is proposed for computing the power factor and the voltage at the motor terminals. It includes a parallel resistance that accounts for the iron losses. They are calculated by the loss model that accounts for the stator and rotor iron losses. Furthermore, we introduce a thermal equivalent circuit for the concentrated end-winding. It is a part of the proposed 3D nodal thermal network that computes the temperature of the motor. Mechanical constraints are also taken into account by the mean of the developed mechanical model. It calculates the forces acting on the iron bridges and the safety factors for breakdown and fatigue.

In the next sections, the magnetic, the electrical, the loss, the thermal and the mechanical models will be detailed. The coupled multi-physics model will be defined and experimentally validated. Finally, the bi-objective optimization method will be presented in order to design the motor for a high torque and low speed application. Its results will be shown and discussed.

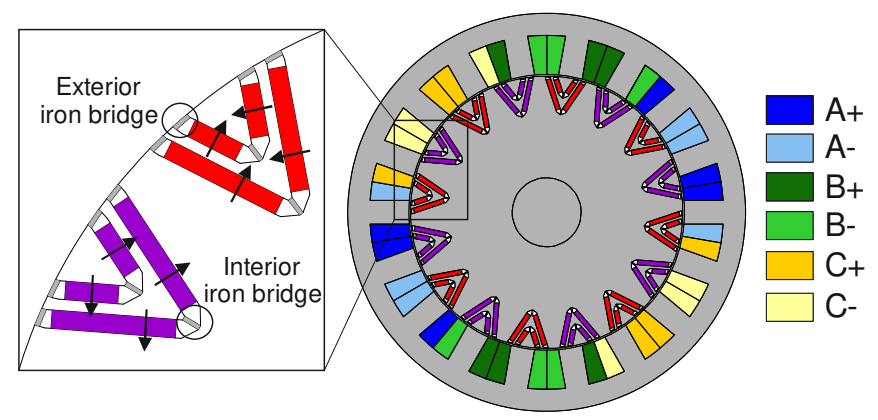

Fig. 1. Studied motor structure 


\section{MAGNETIC MODEL}

The magnetic model provides the main performances of the motor in terms of torque, internal power factor and internal voltage. It relies on two fundamental laws of electromagnetism: Ampere's theorem and the flux conservation law. Our previous work gives a detailed description and analysis of the magnetic model [14]. In this article, we will present the main guidelines of the model with the results compared to a $2 \mathrm{D}$ finite element model.

\section{A. Stator flux density}

The modeled structure has a wide slot opening that allows an easier insertion of the concentrated tooth winding during the manufacturing process. The stator slotting effect is taken into account by calculating an additional air-gap length under the slot opening which leads to the total airgap length $e_{\text {tot }}$.

Fig. 2 shows the flux lines between the airgap and the stator tooth. $\theta_{\tau s t}$ is the tooth pitch, $\theta_{s t}$ is the tooth angular span, $\theta_{i}$ is angular position of the center of the $\mathrm{i}^{\text {th }}$ tooth and $w_{\text {slot }}$ is the slot width. Additionally, the tangential leakage flux that links two adjacent teeth is taken into account. Ampere's theorem is written on paths along the tooth height $h_{s t}$ as shown in Fig. 3.

The flux conservation law is applied between the tangential leakage flux in stator slots $\phi_{\text {lf_slot }}$ and the slot flux entering the tooth $\phi_{\text {st_slot }}$. The stator yoke flux density is calculated using the flux conservation equation between the stator teeth and the yoke over a variation of $\Delta \theta=1^{\circ}$ elec (electrical degree).

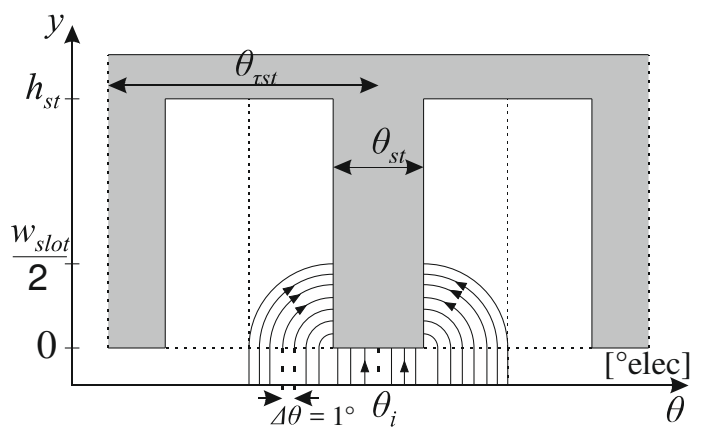

Fig. 2. Flux lines between the airgap and the stator tooth

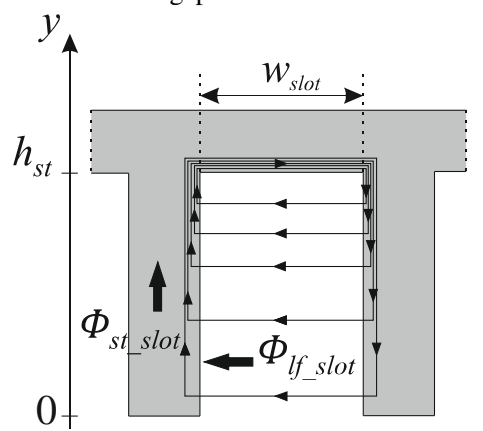

Fig. 3. Tangential leakage flux in the stator slot

\section{B. Rotor flux density}

Fig. 4 shows one rotor pole with V-shape flux-barriers that are filled with magnets. The iron piece between two fluxbarriers is called "flux-guide" (green area in Fig. 4). Each rotor pole is divided into two zones $(z=1,2)$. A linear interpolation is used between the boundary flux densities $B_{f g}$ and $B_{f g f}$ in order to compute the interior flux densities of each flux-guide along its mean path (Fig. 5a).
The structure of the rotor presents interior and exterior iron bridges (Fig. 1). Since the iron bridges are generally saturated, the area near the exterior iron bridges is modeled separately (Fig. 5b). We assume a linear variation of the flux density between two bridges in the $\theta$-axis $\left(B_{x}(\theta)\right.$ between $B_{e b f}$ and $\left.B_{e b 0}\right)$. An average value of the flux density in the y-axis $B_{y}$ is calculated (between $B_{f g f}$ and the airgap flux density between the bridges $\left.B_{\text {ag_avg }}\right)$. Thus, the flux-guide local flux density is given by:

$$
B_{\text {local }}(\theta)=\sqrt{B_{x}(\theta)^{2}+B_{y}^{2}}
$$

\section{Equations of the global system}

The model considers the non-linearity of the ferromagnetic material. Due to magnetic symmetry, half of the machine is modeled. The analytical model computes the normal component of the airgap flux density over one electrical period $\left(360^{\circ} \mathrm{elec}\right)$. Ampere's theorem is applied along five contours $\left(\mathrm{C}_{1}\right.$ to $\left.\mathrm{C}_{5}\right)$ shown in Fig. 4. For the first contour it is given by:

$$
\begin{aligned}
& H_{a g}^{(\theta)} e_{t o t}^{(\theta)}-H_{a g}^{(360)} e_{t o t}^{(360)}+A t_{s}^{(\theta)}-A t_{s}^{(360)} \\
& +A t_{r}^{(\theta)}-A t_{r}^{(360)}+m m f^{(\theta)}-m m f^{(360)}=0
\end{aligned}
$$

where, $m m f$ is the magnetomotive force due to the stator winding, $A t_{s}$ and $A t_{r}$ are the magnetomotive force drop in the stator and the rotor paths respectively. The expressions of contours $\mathrm{C}_{2}$ to $\mathrm{C}_{5}$, the flux density of the iron bridges along with all the details of the magnetic model are given in [14].

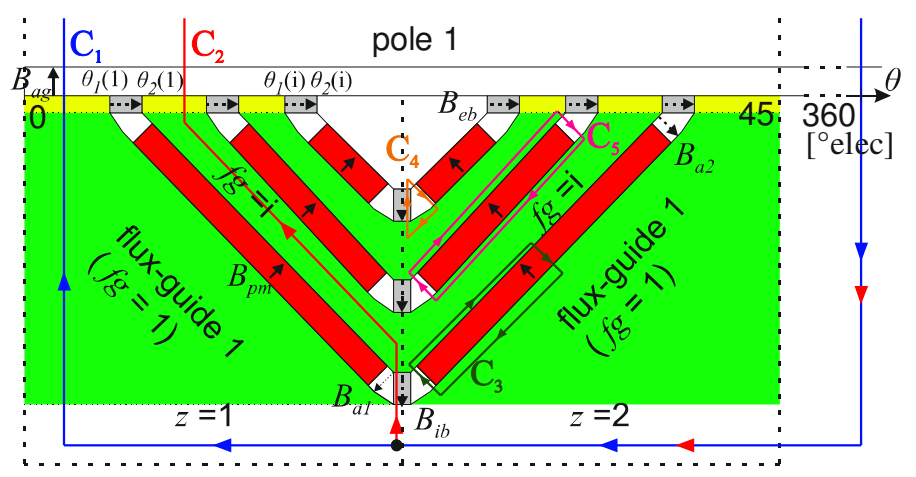

Fig. 4. Motor general schematic and flux paths

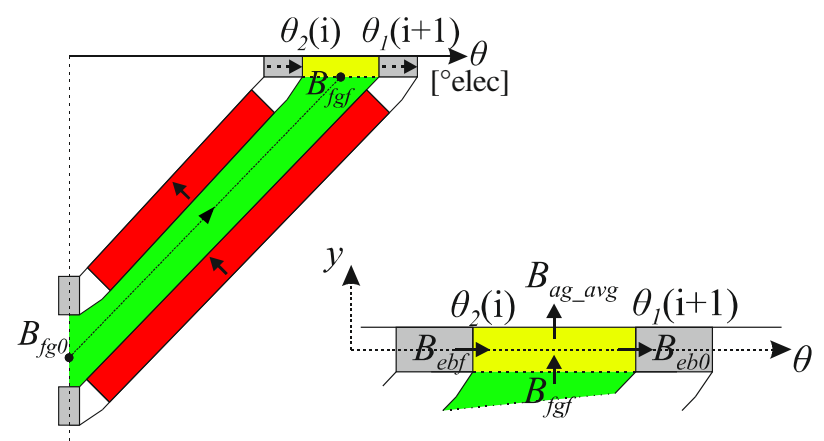

(a)

(b)

Fig. 5. Flux density mean path in a rotor flux-guide (a). Local flux density near the exterior iron bridge (b)

The non-linear equations are solved using Broyden's method. It is a quasi-Newton method that calculates the Jacobian at the first iteration and updates it for the other ones. 


\section{Performance calculation}

The airgap flux density is used to calculate the flux linkages $\left(\phi_{A}, \phi_{B}, \phi_{C}\right)$. The slot leakage flux $\phi_{s t_{l f}}$ is added to obtain the total flux linked by the stator coils. Equation (3) gives the expression of phase- $\mathrm{A}$ flux linkage. For the other phases it is obtained by replacing the subscript A by B and C.

$$
\phi_{A}=\frac{N_{c s}}{N_{c p}} N_{s} \sum_{k=1}^{m} R_{s i} L \int_{\theta_{A-k}}^{\theta_{A+}{ }_{k}} B_{a g}(\theta) d \theta+\phi_{s t_{l f}}
$$

where $\theta_{A+}$ and $\theta_{A-}$ are the center angular position of the coils A+ and A- (Fig. 1), $N_{s}$ is the number of turns per coil, $N_{c s}$ is the number of circuit in series per phase, $N_{c p}$ is the number of circuits in parallel per phase, $m$ is the number of coils per phase per electrical period, $L$ is the stack length and $R_{s i}$ is the stator interior radius. The d-q axis flux linkages $\left(\phi_{d}, \phi_{q}\right)$ are then computed using Park's transformation. The internal current and internal voltage vectors are given by:

$$
\begin{gathered}
\bar{I}_{i n t}=i_{d_{\text {int }}}+j i_{q_{\text {int }}} \\
\bar{V}_{\text {int }}=-\omega \phi_{q}+j \omega \phi_{d}
\end{gathered}
$$

The current angle $\alpha$ is defined as the angle between the internal current vector and the q-axis (Fig. 6).

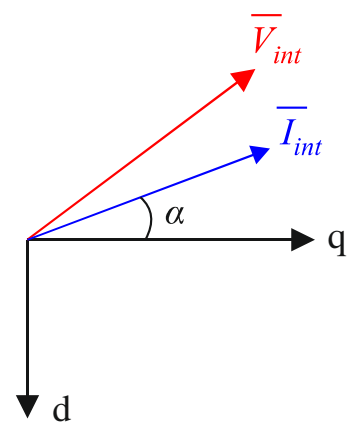

Fig. 6 Current and voltage vectors in d-q diagram

The average torque $\left(T_{a v g}\right)$, the internal power factor $\left(P F_{\text {int }}\right)$ and the internal voltage $\left(V_{\text {int }}\right)$ are calculated at 4 static positions for an accurate estimation [15]. They are given by (6), (7) and (8) respectively.

$$
\begin{gathered}
T_{a v g}=(3 p / 2)\left(\phi_{d} i_{q_{i n t}}-\phi_{q} i_{d_{\text {int }}}\right) \\
P F_{\text {int }}=\cos \left(\tan ^{-1}\left(-\phi_{d} / \phi_{q}\right)-\tan ^{-1}\left(i_{q_{\text {int }}} / i_{d_{\text {int }}}\right)\right) \\
V_{\text {int }}=\omega \sqrt{\phi_{d}^{2}+\phi_{q}^{2}}
\end{gathered}
$$

\section{E. Finite element validation}

The geometry and specifications of the studied motor $M_{l}$ are reported in TABLE I. A 2D finite element model is simulated using FEMM and its results are compared with the analytical model at two current levels: 28 A and 43 A (rms). The average torque, the power factor and the voltage are given in Fig. 7a, Fig. 7b and Fig. 7c respectively.

The Analytical magnetic Model (AM) shows very good concordance with the Finite Element Analysis (FEA). The discrepancy is below $2 \%$ [14].

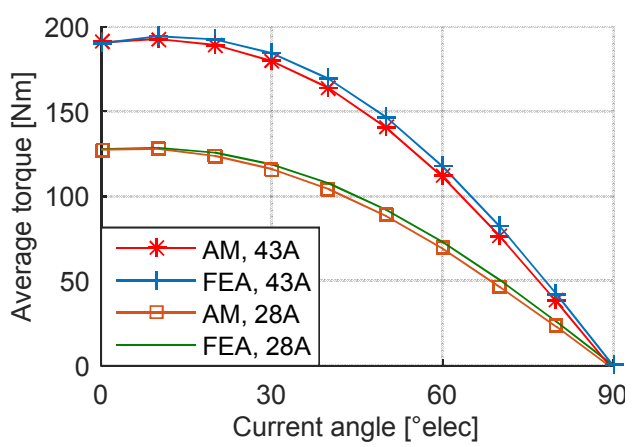

(a) Average torque

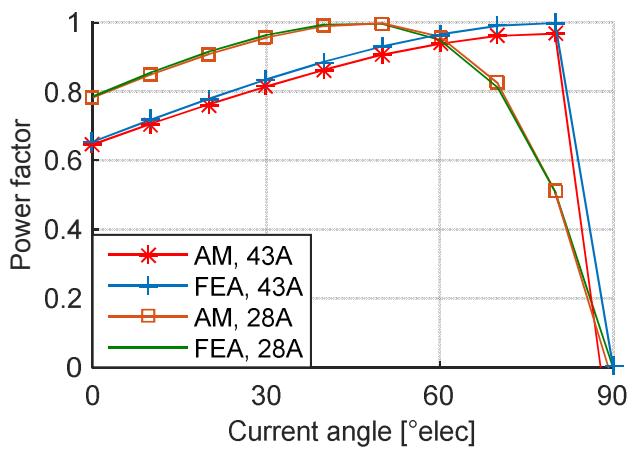

(b) Power factor

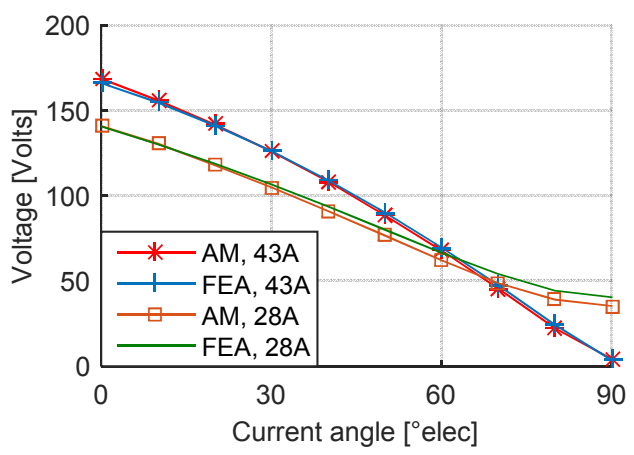

(c) Voltage

Fig. 7. Comparison between AM and FEA

The 18/16 structure allows the development of a smooth torque [6]. Thus, the calculation of the torque ripple is not included in the AM. However, the cogging torque is given in Fig. 8a. Besides, an FEA at $43 \mathrm{~A}$ at a current angle of $10^{\circ} \mathrm{elec}$ is used to verify the torque quality of the motor $\mathrm{M}_{1}$. It shows a low torque ripple of $4.2 \%$ (Fig. 8 b).

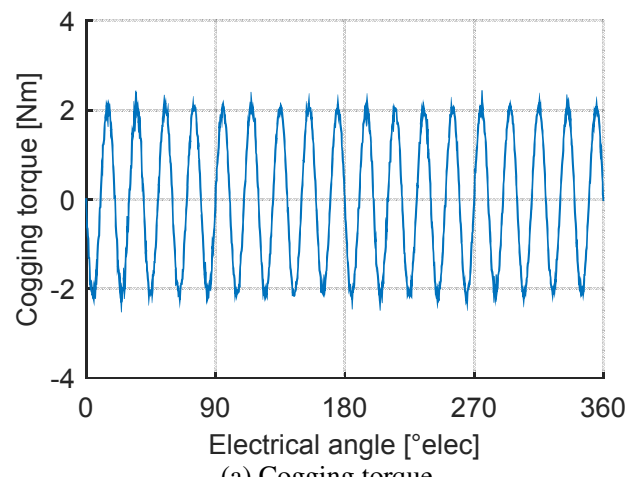

(a) Cogging torque 


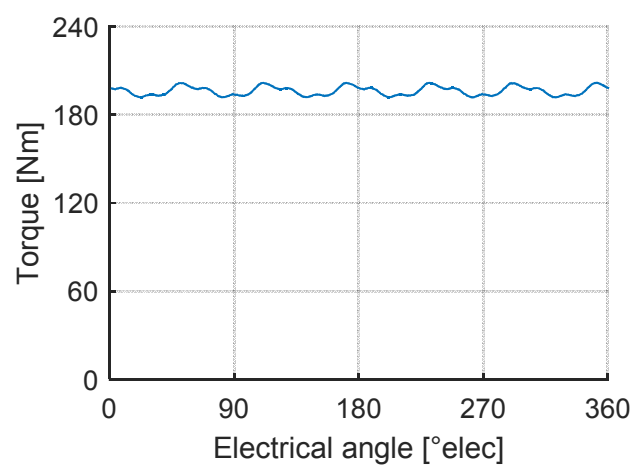

(b) Torque ripple

Fig. 8. Torque ripple and cogging torque of motor $M_{l}$

\section{F. Computational time}

The AM and the FEA are computed using Intel® Core ${ }^{\mathrm{TM}}$ i7-4600U CPU @2.10GHz 2.70GHz with 16GB RAM. The FEA has about 20000 nodes and about 40000 elements. The average computational time of one calculation step is $3.1 \mathrm{~s}$ for the AM and 17s for the FEA. This makes the analytical model about 5 times faster than the finite element model.

TABLE I

MOTOR GEOMETRY AND SPECIFICATIONS

\begin{tabular}{cc}
\multicolumn{2}{c}{ MOTOR GEOMETRY AND SPECIFICATIONS } \\
\hline \hline & $M_{1}$ \\
\hline Stator exterior radius $(\mathrm{mm})$ & 130 \\
Stator interior radius $(\mathrm{mm})$ & 90 \\
Axial length $(\mathrm{mm})$ & 200 \\
Airgap length $(\mathrm{mm})$ & 1 \\
Exterior iron bridge width $(\mathrm{mm})$ & 0.75 \\
Interior iron bridge width $(\mathrm{mm})$ & 0.7 \\
Tooth width $(\mathrm{mm})$ & 11.6 \\
Slot opening angle $\left({ }^{\circ}\right)$ & 13.5 \\
Ferrite magnets remanence $(\mathrm{T})$ & 0.4 \\
Rotation speed (rpm) & 500 \\
Number of turns per coil & 18
\end{tabular}

\section{ELECTRICAL MODEL}

The magnetic model delivers the internal power factor and the internal voltage $\left(V_{\text {int }}\right)$ of the motor. However, in order to calculate the power factor and the voltage at the motor terminals we need to calculate the phase resistance $R_{p h}$ and the end-winding leakage inductance per phase $L_{e w_{p h}}$.The electrical schematic of one phase of the motor is given in Fig. 9. The resistance per phase is given by:

$$
R_{p h}=\rho_{\text {Cu }} \frac{N_{s}^{2} l_{\text {turn }}}{K_{\text {fill }} S_{\text {coil }}} \frac{N c s}{N c p} \text { with } S_{\text {coil }}=w_{\text {coil }} \times h_{\text {coil }}
$$

where $\rho_{\text {Cu }}, l_{\text {turn }}, K_{\text {fill }}, S_{\text {coil }}, w_{\text {coil }}$ and $h_{\text {coil }}$ are the copper resistivity, the average turn length, the fill factor, the coil cross-sectional area, the coil width and the coil height respectively. The end-winding leakage inductance per phase is calculated using (10) given in [16] and is based on the geometry shown in Fig. 10.

$$
\begin{gathered}
L_{e w_{p h}}=\frac{\mu_{0} l_{e w} N_{s}^{2}}{2 \pi} \ln \left(\frac{r}{R_{c}}\right) \frac{N c s}{N c p} \\
\text { with } r=R_{c}+\frac{w_{c o i l}}{2}+\frac{w_{s t}}{2} \text { and } \pi R_{c}^{2}=S_{\text {coil }}
\end{gathered}
$$

where $\mu_{0}$ is the vacuum permeability and $l_{e w}$ is the end- winding average length. The iron losses $P_{i l}$ (calculated in section IV.B) are modeled by the mean of a parallel resistance $R_{i l}$ calculated as follows:

$$
R_{i l}=3 \frac{V_{i n t_{r m s}}^{2}}{P_{i l}}
$$

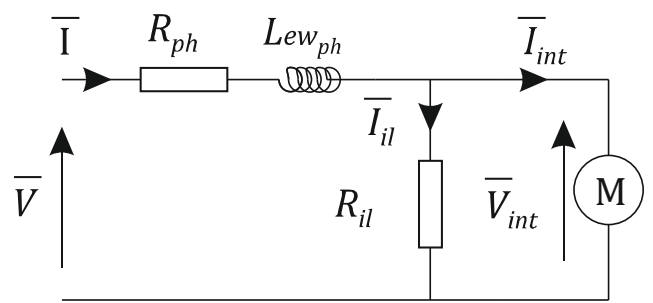

Fig. 9. Electrical schematic

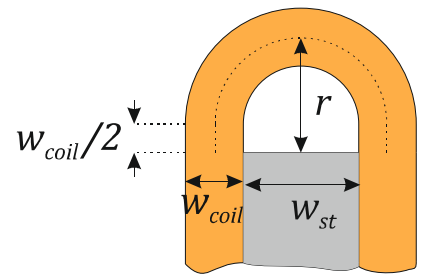

Fig. 10. End-winding geometry

The d-q axis current and voltage at the motor terminals are obtained by applying Kirchhoff's law to the circuit given in Fig. 9. This leads to the following expressions:

$$
\begin{gathered}
i_{d}=i_{d_{\text {int }}}-\left(\omega \phi_{q}\right) / R_{i l} \\
i_{q}=i_{q_{\text {int }}}+\left(\omega \phi_{d}\right) / R_{i l} \\
v_{d}=-\omega \phi_{q}+R_{p h} i_{d}-L_{e w_{p h}} \omega i_{q} \\
v_{q}=+\omega \phi_{d}+R_{p h} i_{q}+L_{e w_{p h}} \omega i_{d}
\end{gathered}
$$

\section{LOSS MODEL}

The heat generation in an electrical motor is mainly caused by the losses that appear in the copper, the iron and the magnets. High resistivity ferrite magnets leads to negligible magnet losses [17].

\section{A. Copper losses}

$R_{p h}$ given by (9) and the current $r m s$ value per phase $I_{r m s}$ are used to calculate the copper losses as follows:

$$
P_{C u}=3 R_{p h} I_{r m s}^{2}
$$

\section{B. Iron losses}

The stator iron loss components are calculated separately for sinusoidal flux density. This can be extended to nonsinusoidal flux density by applying the principle of superposition using the following expression at the different harmonic frequencies [18]:

$$
\begin{aligned}
& P_{\text {stator }}(B, f)=k_{H} f \hat{B}^{\alpha_{i r}} \\
& +k_{E C} \sum_{k=1}^{\infty}(k f)^{\frac{3}{2}} B_{k}{ }^{2} \frac{\sinh (\gamma \sqrt{k f)}-\sin (\gamma \sqrt{k f})}{\cosh (\gamma \sqrt{k f)}-\cos (\gamma \sqrt{k f})} \\
& +k_{E X C} f^{\frac{3}{2}} \hat{B}^{\frac{3}{2}}[W / k g]
\end{aligned}
$$


where $B_{k}$ is the amplitude of the $\mathrm{k}^{\text {th }}$ rank of the Fourier series decomposition and $\hat{B}$ is the amplitude of the magnetic flux density. Equation (17) is applied to the stator teeth $\left(P_{s t}\right)$ and to the yoke $\left(P_{s y}\right)$ to calculate the total iron losses in the stator. The parameters $k_{H}, \alpha_{i r}, k_{E C}, \gamma$ and $k_{E X C}$ are determined by fitting the losses calculated using (17) to the manufacturer's data. The parameters obtained for the M400P50 sheet steel, used in this design, are reported in TABLE II.

The stator iron loss model was compared to a $2 \mathrm{D}$ finite element model using $\mathrm{JMAG}^{\circledR}$. The results for the motor $M_{l}$ (TABLE I) at $43 \mathrm{~A}$ are given in Fig. 11. It shows a good estimation of the stator iron losses at different current angle.

TABLE II

M400P50 IRON LOSS PARAMETERS

\begin{tabular}{cccccc}
\hline \hline & $k_{H}$ & $\alpha_{i r}$ & $k_{E C}$ & $\gamma$ & $k_{E X C}$ \\
\hline Value & 0.0248 & 1.7297 & 0.0040 & 0.1556 & 0 \\
\hline
\end{tabular}

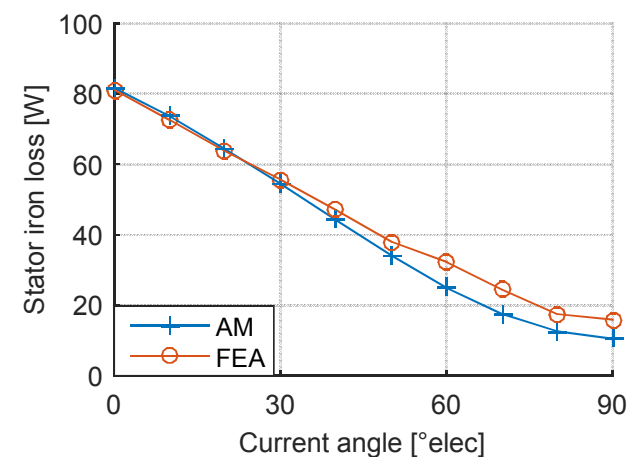

Fig. 11. Comparison of the stator iron loss between the AM and the FEA

On the rotor side, the iron losses can reach significant values due to the presence of the concentrated tooth winding. In fact, the space harmonics component of the stator winding can mainly cause eddy current losses in the rotor [17]. In order to take the rotor iron losses into consideration, we computed them using a 2D finite element model in $\mathrm{JMAG}^{\circledR}$ for the reference motor $M_{l}$. This leads to an average value of the rotor iron losses noted $P_{\text {ref }}$ corresponding to the stack length of the reference motor $l_{\text {ref }}$. Thus, the rotor iron losses for other similar structures having a stack length $l_{s}$ is estimated using simple scaling as given by:

$$
P_{\text {rotor }}=\left(P_{\text {ref }} / l_{\text {ref }}\right) l_{s}
$$

The total iron losses $\left(P_{i l}\right)$ in the motor are given by:

$$
P_{i l}=P_{s t}+P_{s y}+P_{\text {rotor }}
$$

\section{THERMAL MODEL}

Thermal aspects in permanent magnet motors are of great importance since they affect the magnetic and the electric properties of the materials. In this study, a 3D nodal approach is used to calculate the temperature in the different parts of motor by considering the heat flow in the radial and the axial directions [19]. The motor operates at the steady state. Thus, the model is based on equivalent thermal resistances that account for the conductive heat transfer in solids and for the convective heat transfer in the airgap, the endcap and the casing. An axial symmetry is assumed so half of the machine can be modeled.
The governing equations are based on the method described in [19]. However, some thermal properties involved in the modeling are relatively difficult to define. This is the case of the stator slot because this area is non-homogenous and the case of the airgap because of the fluid dynamics that govern the heat transfer. Thus, the winding thermal conductivity in the radial direction is homogenized using (20) [20]. It is equal to $0.748 \mathrm{~W} / \mathrm{m} / \mathrm{K}$. In the axial direction, the winding thermal conductivity is assumed to be equal to the copper thermal conductivity $(400 \mathrm{~W} / \mathrm{m} / \mathrm{K})$.

$$
\lambda_{\mathrm{w}}=\lambda_{\text {res }} \frac{\left(1+K_{\text {fill }}\right) \lambda_{c u}+\left(1-K_{\text {fill }}\right) \lambda_{\text {res }}}{\left(1-K_{\text {fill }}\right) \lambda_{c u}+\left(1+K_{\text {fill }}\right) \lambda_{\text {res }}}
$$

where $\lambda_{C u}$ and $\lambda_{\text {res }}$ are the copper and the resin thermal conductivities respectively. Concerning the airgap, the calculation of the convective heat transfer coefficient is based on Taylor $(\mathrm{Ta})$ and Nusselt $(\mathrm{Nu})$ numbers [21]. It is given by:

$$
h_{\text {airgap }}=\frac{N u \lambda_{\text {air }}}{2 e_{\text {airgap }}}
$$

where $\lambda_{\text {air }}$ is the air thermal conductivity and $e_{\text {airgap }}$ is the airgap length. The thermal network takes into consideration the insulation between the stator teeth and the slot winding. Besides, the contact resistance between the stator back iron and the casing is also considered.

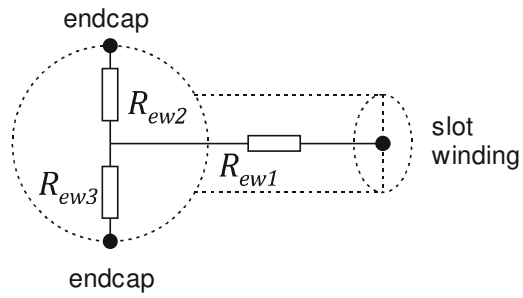

Fig. 12. End-winding equivalent circuit

As for the end-winding (Fig. 10), they are modeled by three thermal resistances (Fig. 12): $R_{e w l}$ accounting for the axial heat transfer, $R_{e w 2}$ and $R_{e w 3}$ accounting for the radial heat transfer of the curved parts. In case of distributed winding, the author in [19] modeled the curved parts as a toroidal structure. However, because we are dealing with concentrated tooth winding, we propose to model the curved parts as cylindrical structures having a length equal to $l_{e w}$. The resistances are given by (22) and (23) where $N_{\text {slots }}$ is the number of slots and $k_{h s}$ is a hot-spot to mean temperature ratio [19].

$$
\begin{gathered}
R_{e w 1}=\frac{l_{e w} k_{h s}}{\lambda_{c u} S_{\text {coil }} K_{\text {fill }}} \frac{1}{N_{\text {slots }}} \\
R_{e w 2}=R_{e w 3}=\frac{k_{h s}}{\lambda_{w} \pi l_{e w}} \frac{1}{N_{\text {slots }}}
\end{gathered}
$$

The general scheme of the thermal network is shown in Fig. 13. The reference temperature is the ambient temperature $T_{0}$. The heat sources are the copper losses in the slot winding and in the end-winding, the iron losses in the stator teeth, the stator yoke and the rotor. The motor is totally enclosed and fan cooled (TEFC). The fan rotates at a constant speed with a flow rate equal to $80.4 \mathrm{dm}^{3} / \mathrm{s}$. The thermal model is a linear system given by:

$$
[A]^{T}[G][A][T]=[P]
$$


where $[\boldsymbol{A}]$ is a matrix that describes the heat flow direction in a branch (i.e. between two nodes), $[\boldsymbol{G}]$ is a diagonal matrix that contains the conductance of each branch, $[\boldsymbol{P}]$ is a vector that contains the heat sources at each node and $[\boldsymbol{T}]$ is a vector that contains the nodal temperatures.

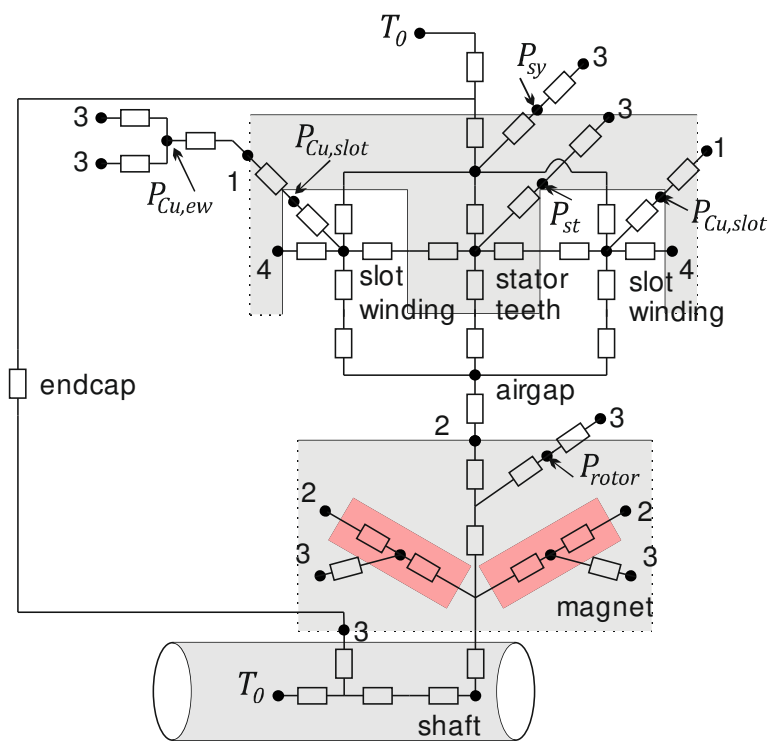

Fig. 13. Thermal network general scheme

The resolution of (24) leads to the nodal temperatures, among which the copper and the magnet temperatures are of interest. The results are compared with MotorCad ${ }^{\circledR}$ and reported in TABLE III. They show that the nodal thermal network is capable of predicting the temperature in the motor with a discrepancy around $4 \%$.

TABLE III

TEMPERATURE COMPARISON WITH $\mathrm{P}_{\text {ROTOR }}=60 \mathrm{~W}$ $\mathrm{P}_{\text {STATOR }}=130 \mathrm{~W}$ AND $\mathrm{P}_{\mathrm{CU}}=800 \mathrm{~W}$

\begin{tabular}{cccc}
\hline \hline & $\begin{array}{c}\text { Model } \\
\left({ }^{\circ} \mathrm{C}\right)\end{array}$ & $\begin{array}{c}\text { MotorCad }^{\circledR} \\
\left({ }^{\circ} \mathrm{C}\right)\end{array}$ & $\begin{array}{c}\text { Discrepancy } \\
(\%)\end{array}$ \\
\hline End-winding & 80.77 & 77.57 & 4.12 \\
Slot winding & 74.05 & 71.07 & 4.19 \\
Magnets & 71.33 & 69 & 3.38 \\
\hline
\end{tabular}

\section{MeChaniCAL MODEL}

The studied IPM motor presents interior and exterior iron bridges on the rotor side (Fig. 1). Generally, the iron bridges are the weakest points of the structure and undergo the main mechanical stress. Even though the targeted application rotates at a low speed, a mechanical model is developed in order to evaluate the safety factors for two main mechanical failures: breakdown and fatigue.

Fig. 14 shows the main forces acting on a rotor pole. It is assumed that the centrifugal force $\left(F_{G}\right)$ is the only mechanical force acting on the rotor [22]. The flexion is neglected and the iron bridges are modeled as springs. Thus, Hook's law is expressed by:

$$
F_{i}=k_{i} \delta_{i}
$$

where $k$ is the stiffness of the iron bridge that reflects the elasticity of the iron material. $\delta$ is the displacement caused by the force $F$. The subscript ' $i$ ' corresponds to ' $t$ ' which represents the tangential component related to the exterior iron bridge, or to ' $r$ ' which represent the radial component related to the interior iron bridge.

The pole structure is assumed to be rigid so the radial displacement of the tangential iron bridge $u_{t}$ is equal to that of the interior iron bridge $\delta_{r}$. The projection of the equilibrium equation on the radial axis (Fig. 14) leads to the following expressions of the forces:

$$
\begin{aligned}
& F_{t}=F_{G} \frac{\cos \left(\theta_{t}\right)}{2 \cos ^{2}\left(\theta_{t}\right)+\left(k_{r} / k_{t}\right)} \\
& F_{r}=F_{G} \frac{1}{1+2\left(k_{t} / k_{r}\right) \cos ^{2}\left(\theta_{t}\right)}
\end{aligned}
$$

where $\theta_{t}$ is the angle between $F_{t}$ and the radial axis. The nominal stresses are then expressed by:

$$
\sigma_{\text {nom }_{i}}=F_{i} / A_{i}
$$

where $A_{i}$ is the area of the surface on which the force is applied for the interior or exterior iron bridges. The safety factors for breakdown $S_{B}$ and for fatigue $S_{F}$ are given by:

$$
\begin{gathered}
S_{B_{i}}=\sigma_{Y} / \sigma_{\text {nom }_{i}} \\
S_{F_{i}}=\sigma_{D} / \sigma_{\text {peak }_{i}} \text { with } \sigma_{\text {peak }}=\sigma_{\text {nom }} K_{t}
\end{gathered}
$$

where $\sigma_{Y}$ and $\sigma_{D}$ are the elastic limit and the allowable fatigue stress of the material respectively. $K_{t}$ is a stress concentration coefficient that depends on the geometry [23]. The calculated safety factors have to be greater than 1.5 to ensure the mechanical strength of the structure.

The analytical calculation of the nominal stresses was compared to a 2D finite element model using JMAG ${ }^{\circledR}$. Fig. 15 shows the stress distribution at $500 \mathrm{rpm}$ for the motor $M_{1}$ (TABLE I). The results for the interior and exterior iron bridges are given at two rotational speeds: $500 \mathrm{rpm}$ (TABLE IV) and $1000 \mathrm{rpm}$ (TABLE V).

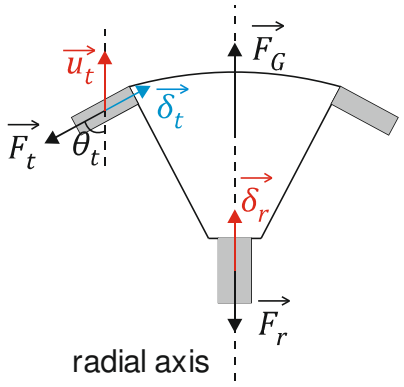

Fig. 14. Main forces on a rotor pole

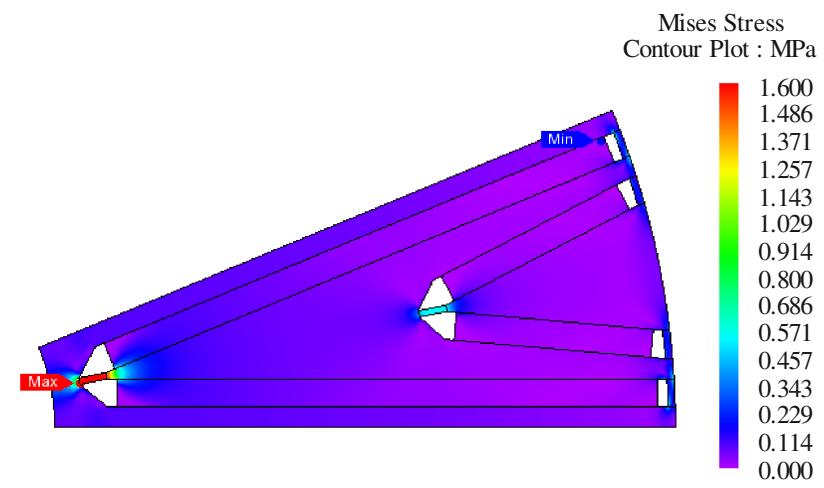

Fig. 15. Stress distribution at $500 \mathrm{rpm}$ 
TABLE IV

NOMINAL STRESS COMPARISON AT 500 RPM

\begin{tabular}{|c|c|c|c|}
\hline & $\begin{array}{l}\text { Model } \\
(\mathrm{MPa})\end{array}$ & $\begin{array}{l}\text { FEA } \\
(\mathrm{MPa}) \\
\end{array}$ & $\begin{array}{c}\text { Discrepancy } \\
(\%) \\
\end{array}$ \\
\hline $\begin{array}{c}\text { Interior iron } \\
\text { bridge (barrier 1) }\end{array}$ & 1.65 & 1.62 & 1.8 \\
\hline $\begin{array}{c}\text { Interior iron } \\
\text { bridge (barrier 2) }\end{array}$ & 0.52 & 0.54 & 3.7 \\
\hline $\begin{array}{c}\text { Exterior iron } \\
\text { bridge (barrier 1) }\end{array}$ & 0.32 & 0.3 & 6.6 \\
\hline $\begin{array}{c}\text { Exterior iron } \\
\text { bridge (barrier 2) }\end{array}$ & 0.15 & 0.16 & 6.2 \\
\hline \multicolumn{4}{|c|}{$\begin{array}{c}\text { TABLE V } \\
\text { NOMINAL STRESS COMPARISON AT } 1000 \text { RPM } \\
\end{array}$} \\
\hline & $\begin{array}{l}\text { Model } \\
(\mathrm{MPa}) \\
\end{array}$ & $\begin{array}{l}\text { FEA } \\
(\mathrm{MPa}) \\
\end{array}$ & $\begin{array}{c}\text { Discrepancy } \\
(\%) \\
\end{array}$ \\
\hline $\begin{array}{c}\text { Interior iron } \\
\text { bridge (barrier 1) }\end{array}$ & 6.6 & 6.47 & 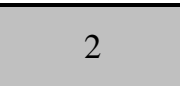 \\
\hline $\begin{array}{l}\text { Interior iron } \\
\text { bridge (barrier 2) }\end{array}$ & 2.1 & 2.18 & 3.7 \\
\hline $\begin{array}{c}\text { Exterior iron } \\
\text { bridge (barrier 1) }\end{array}$ & 1.02 & 0.96 & 6.2 \\
\hline $\begin{array}{c}\text { Exterior iron } \\
\text { bridge (barrier 2) }\end{array}$ & 0.68 & 0.73 & 6.8 \\
\hline
\end{tabular}

The results show that the interior iron bridges are the one that encounter the main stress. The discrepancy with the FEA is around $4 \%$.

\section{COUPLED MULTI-PHYSICS MODEL}

The different analytical models are coupled via their inputs and their outputs. Fig. 16 shows a block diagram of the multiphysics coupling. The geometrical dimensions are the main inputs for the coupled model. The magnetic model delivers the electromagnetic torque, the internal power factor and the internal voltage. They are used by the electrical model in order to calculate the power factor and the voltage at the motor terminals. The loss model uses the flux density in the stator given by the magnetic model along with the phase resistance to compute the iron and the copper losses of the motor. The losses are used as inputs for the thermal model that gives the temperature across the structure. The mechanical model calculates the safety factors.

The temperature of the magnets is a key parameter that affects the magnetic performances of the motor by changing the magnet remanence according to (31). The winding temperature changes the copper resistivity according to (32) and affects the phase resistance. Thus, the temperature of the magnets $\left(T_{p m}\right)$ and the copper $\left(T_{C u}\right)$ are used to update the magnetic and the electrical models. The thermal stability is obtained by solving the coupled problem using a fixed point method [18].

$$
\begin{gathered}
B_{r}\left(T_{p m}\right)=B_{r}\left(T_{0}\right)\left(1+\alpha_{B_{r}}\left(T_{p m}-T_{0}\right)\right) \\
\rho\left(T_{C u}\right)=\rho\left(T_{0}\right)\left(1+\alpha_{C u}\left(T_{C u}-T_{0}\right)\right)
\end{gathered}
$$

where $B_{r}$ is the magnet remanent flux density and $\rho$ is the copper resistivity. $\alpha_{B r}$ and $\alpha_{C u}$ are the temperature coefficients of the permanent magnets and the copper respectively.

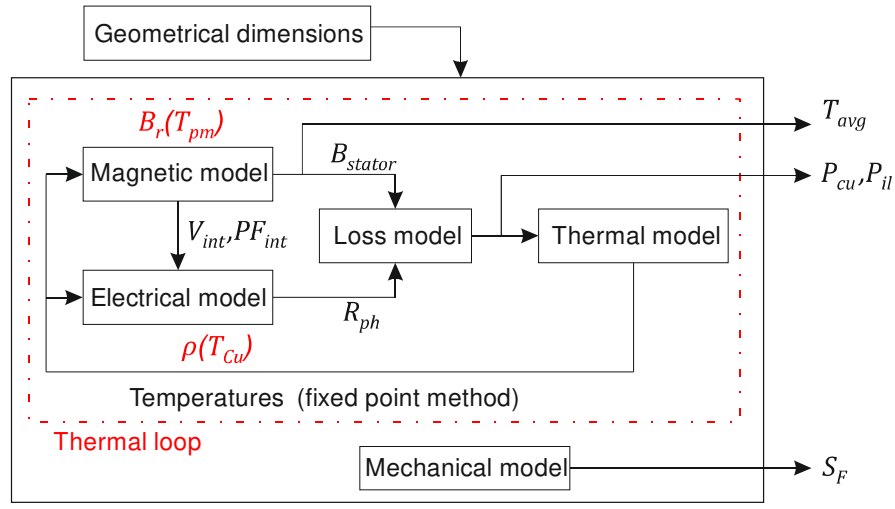

Fig. 16. Multi-physics coupling block diagram

\section{EXPERIMENTAL VALIDATION}

In order to validate the coupled multi-physics analytical model, a prototype motor has been built. The prototype geometrical specifications are those given for the motor $M_{1}$ in TABLE I. Its main characteristics are reported in TABLE VI. The number of turns per coil has been increased compared to the motor $M_{l}$ in order to decrease the current rating of the motor drive and to increase the rated voltage of the prototype. Fig. 17 shows the experimental setup with the prototype motor, the load motor and the motor drive.

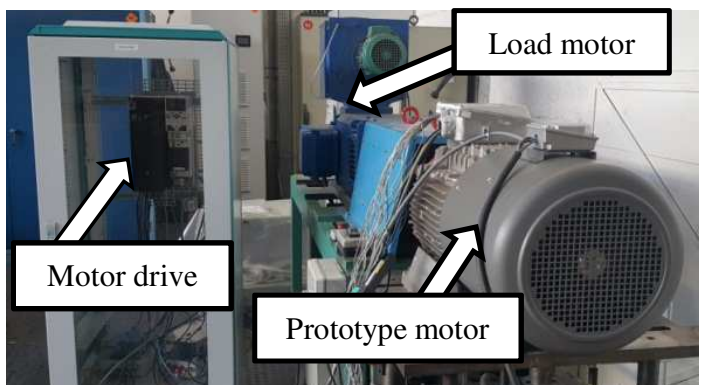

Fig. 17. Experimental setup

TABLE VI

PROTOTYPE MAIN CHARACTERISTICS

\begin{tabular}{cc}
\hline \hline & Value \\
\hline Rated current $(\mathrm{rms})(\mathrm{A})$ & 26 \\
Rated voltage $(\mathrm{rms})(\mathrm{V})$ & 354 \\
Rated torque $(\mathrm{Nm})$ & 200 \\
Rated speed $(\mathrm{rpm})$ & 500
\end{tabular}

Fig. 18 shows the back EMF waveform at rated speed and ambient temperature. The current and the voltage waveforms of the motor at the rated conditions are given in Fig. 19.

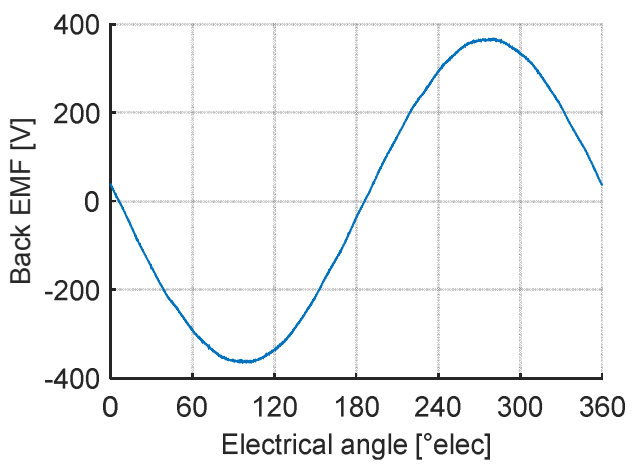

Fig. 18. Experimental back EMF at 500 rpm 


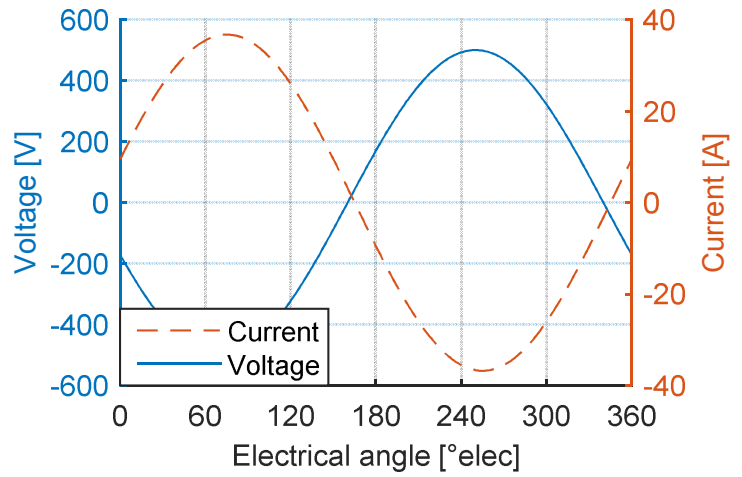

Fig. 19 Experimental current and voltage at rated conditions

The experimental performances were compared to the analytical ones. The results of the average torque, the power factor, the voltage and the efficiency are given in Fig. 20, Fig. 21, Fig. 22 and Fig. 23 respectively. They are plotted for two current values: $12 \mathrm{~A}$ and $26 \mathrm{~A}$.

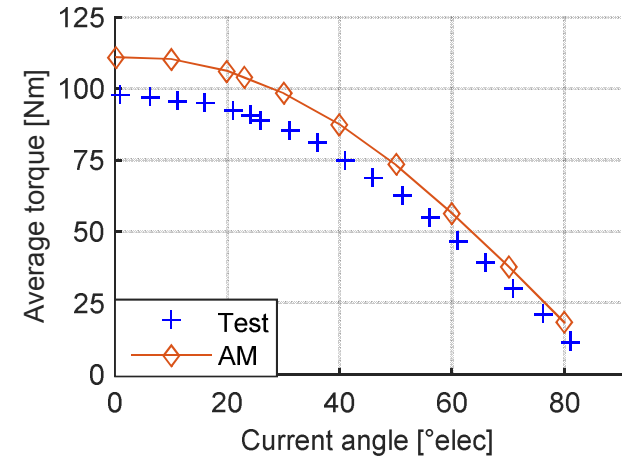

(a) $\mathrm{I}_{\mathrm{rms}}=12 \mathrm{~A}$

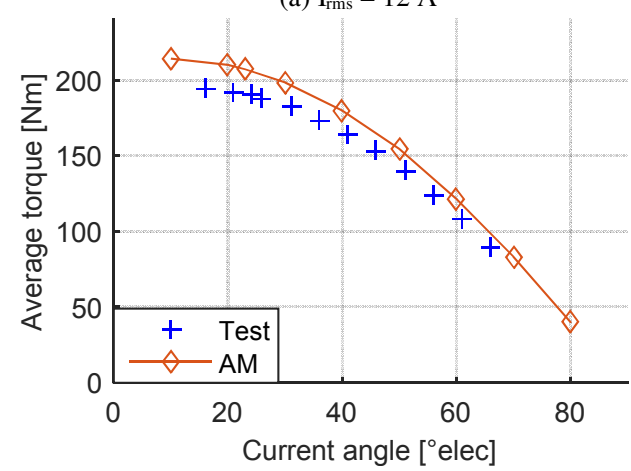

(b) $\mathrm{I}_{\mathrm{rms}}=26 \mathrm{~A}$

Fig. 20. Validation tests - average torque

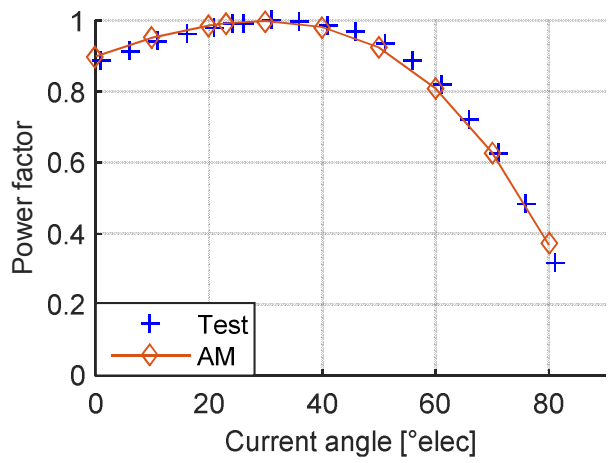

(a) $\mathrm{I}_{\mathrm{rms}}=12 \mathrm{~A}$

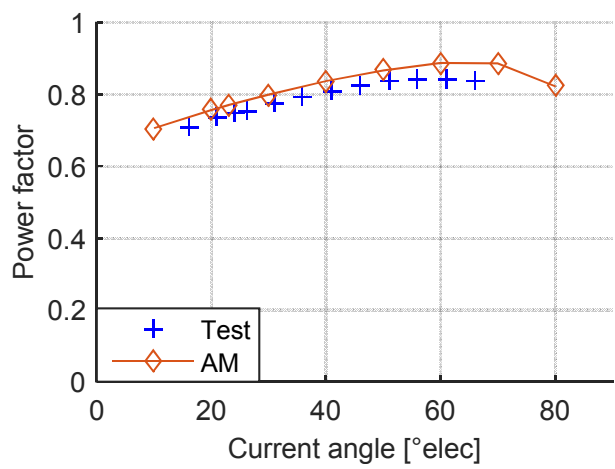

(b) $\mathrm{I}_{\mathrm{rms}}=26 \mathrm{~A}$

Fig. 21. Validation tests - power factor

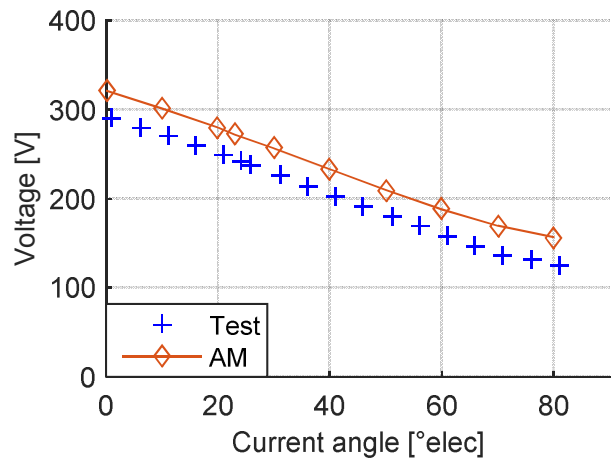

(a) $\mathrm{I}_{\mathrm{rms}}=12 \mathrm{~A}$

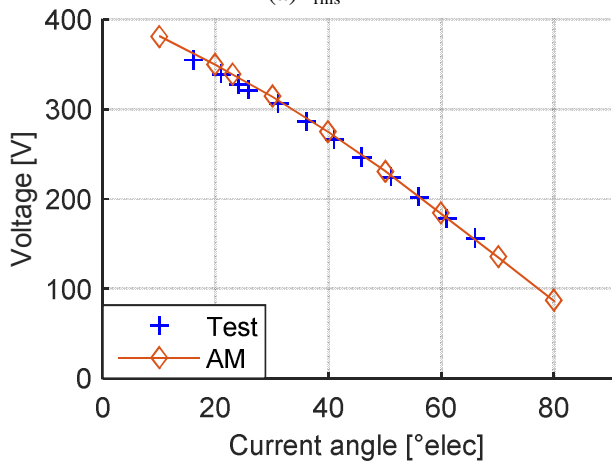

(b) $\mathrm{I}_{\mathrm{rms}}=26 \mathrm{~A}$

Fig. 22. Validation tests - voltage

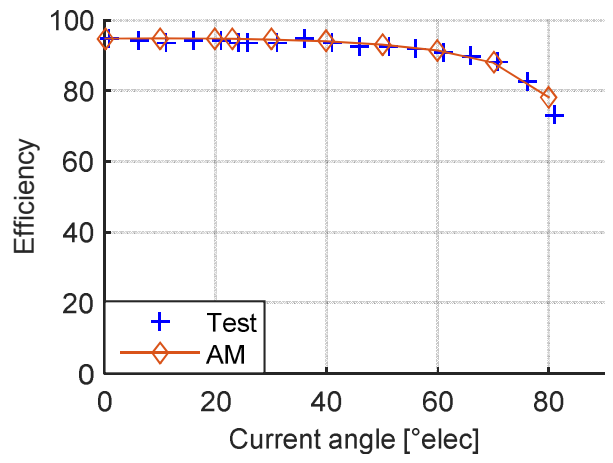

(a) $\mathrm{I}_{\mathrm{rms}}=12 \mathrm{~A}$ 


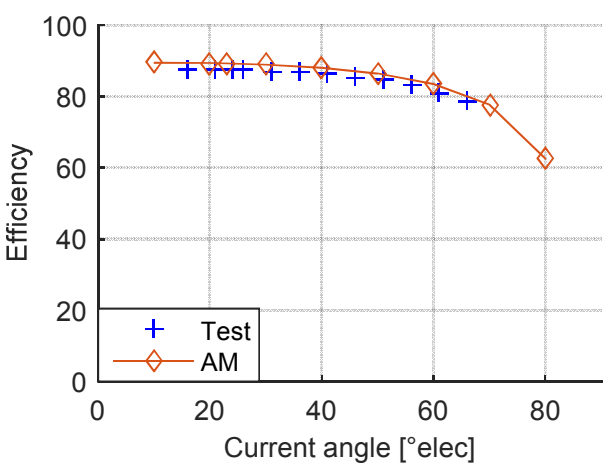

(b) $\mathrm{I}_{\mathrm{rms}}=26 \mathrm{~A}$

Fig. 23. Validation tests - efficiency

The discrepancy at the maximum average torque between the tests and the analytical results is $12.24 \%$ at $12 \mathrm{~A}$ and $7.7 \%$ at $26 \mathrm{~A}$. For the voltage, the discrepancy at low current angle is $10.7 \%$ at $12 \mathrm{~A}$ and $3.4 \%$ at $26 \mathrm{~A}$. This difference between the prototype and the analytical model suggests a higher saturation levels in the steel sheet that can be caused by the manufacturing process especially when cutting the barriers. The power factor and the efficiency of the motor computed by the analytical model match those obtained during the tests with a discrepancy below $2 \%$. This validates the calculation of the phase resistance, the end-winding leakage inductance and the different losses of the motor.

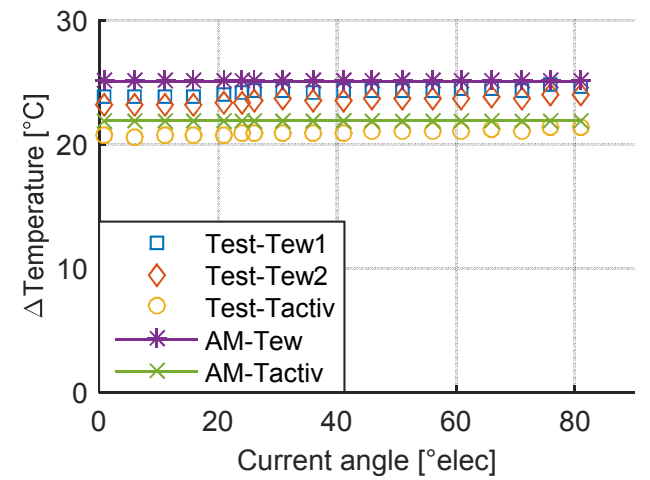

(a) $\mathrm{I}_{\mathrm{rms}}=12 \mathrm{~A}$

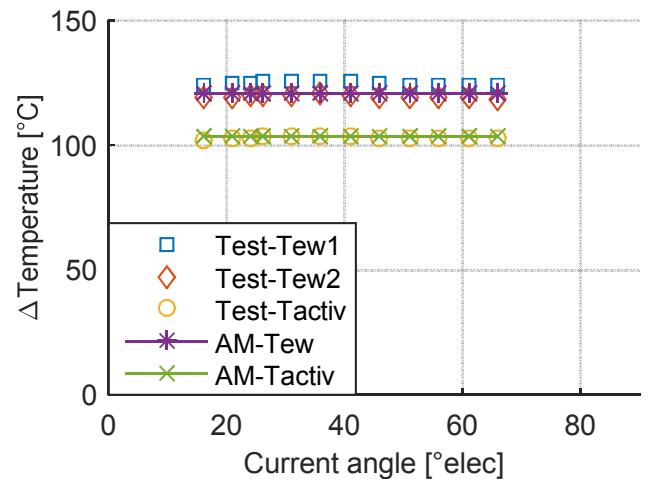

(b) $\mathrm{I}_{\mathrm{rms}}=26 \mathrm{~A}$

Fig. 24. Validation tests - Winding heating temperature

The winding temperature of the prototype motor is monitored using three sensors: two of them are located on the front (Test- $T_{\text {ewl }}$ ) and the rear (Test- $T_{\text {ew2 } 2}$ ) end-winding and another one is located in the middle of the active slot winding $\left(\right.$ Test- $\left.T_{\text {activ }}\right)$. The analytical model delivers the end-winding temperature $\left(\mathrm{AM}-T_{e w}\right)$ and the active winding temperature (AM- $\left.T_{a c t i v}\right)$. Fig. 24a and Fig. 24b show the comparison of the winding heating temperature as a function of the current angle at $12 \mathrm{~A}$ and $26 \mathrm{~A}$ respectively. At both current values, the analytical model shows a very good concordance with the experimental results. The temperature discrepancy does not exceed $\pm 2{ }^{\circ} \mathrm{C}$. Besides, the experimental end-winding temperatures (Test- $\left.T_{e w 1}\right)$ and (Test- $\left.T_{e w 2}\right)$ are very close which justifies the axial symmetry assumption for the thermal model.

The multi-physics analytical model has been experimentally validated. It is able to deliver accurate results with reduced computational time. Thus, it will be used in a multi-physics optimization procedure.

\section{Multi-Physics Model Optimization}

The multi-physics optimization approach allows considering the different physical aspects of the motor and leads to an optimal design that meets the given specifications. In this study, two optimizations are conducted: the first one with fixed exterior radius $\left(R_{\text {ext }}\right)$ and the second one with variable exterior radius.

\section{A. Optimization problem}

In this study, the objectives are maximizing the efficiency $\eta$ and minimizing the cost $c$, their expressions are given by (33) and (34) respectively. Thus, the design problem is turned to a bi-objective optimization problem under constraints.

$$
\begin{gathered}
\eta=\frac{T_{\text {avg }} \Omega}{T_{\text {avg }} \Omega+P_{C u}+P_{i l}} \\
c=\text { cost }_{\text {copper }}+\text { cost }_{\text {iron sheets }}+\text { cost }_{\text {magnets }}
\end{gathered}
$$

where $\Omega$ is the rotational speed in $\mathrm{rad} / \mathrm{s}$.

The lower and upper limits of the optimization variables $x$ are fixed using previous FEA analysis. They are defined in TABLE VII. We have considered 7 geometrical variables shown in Fig. 25. Besides, the stack length, the number of turns per coil, the current angle and the current density are added to the variables.

The targeted machine has to develop an average torque above $210 \mathrm{Nm}$. Its power factor must be greater than 0.85 with a voltage and a current below $365 \mathrm{~V}$ and 40 A respectively (33). Furthermore, a demagnetization constraint is considered. The magnets magnetic field $H_{p m}$ is calculated assuming two times the current value with a current angle of $90^{\circ} \mathrm{elec}$ which reflects a phase opposition between the stator the rotor fluxes [24]. The demagnetization condition assures that $H_{p m}$ is below the intrinsic coercive magnetic field of the ferrite magnets $H_{c J}$ at the ambient temperature.

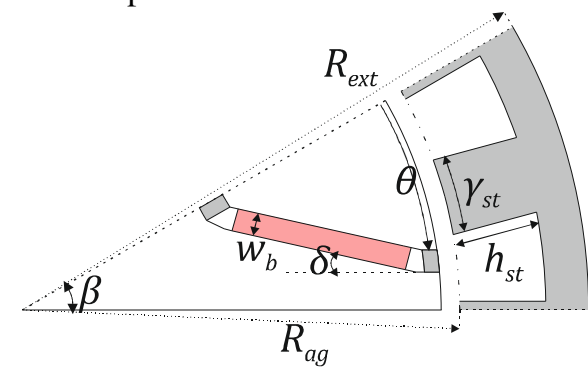

Fig. 25. Geometrical optimization variables 
The optimization problem is formulated as follows:

$$
\begin{gathered}
\left\{\begin{array}{l}
\max \quad \eta(x) \\
\min \quad c(x)
\end{array}\right. \\
\text { Under constraints: } \\
\text { Average torque }>210 \mathrm{Nm} \\
\text { Power factor }>0.85 \\
\text { Voltage }<365 \mathrm{~V} \\
\text { Current }<30 \mathrm{~A} \\
H_{p m}<H_{c J}=275 \mathrm{kA} / \mathrm{m} \\
S_{F}>1.5
\end{gathered}
$$

TABLE VII

OPTIMIZATION VARIABLES

\begin{tabular}{l|l} 
Fixed $\boldsymbol{R}_{\text {ext }}$ & Variable $\boldsymbol{R}_{\text {ext }}$ \\
\hline
\end{tabular}

\begin{tabular}{lcc|cc}
\hline \multicolumn{1}{c}{$x$} & $\min$ & $\max$ & $\min$ & $\max$ \\
Airgap radius: $R_{a g}[\mathrm{~mm}]$ & 80 & 95 & 75 & 120 \\
Tooth angle: $\gamma_{s t}\left[^{\circ}\right]$ & 5 & 12 & 5 & 12 \\
Stack length $L_{s t k}[\mathrm{~mm}]$ & 200 & 250 & 200 & 250 \\
Tooth height: $h_{s t}[\mathrm{~mm}]$ & 15 & 30 & 15 & 30 \\
Number of turns & 15 & 35 & 15 & 35 \\
Barrier titlt angle $: \delta\left[^{\circ}\right]$ & 0 & 6 & 0 & 6 \\
Barrier opening angle ratio: $\theta / \beta$ & 0.1 & 0.9 & 0.1 & 0.9 \\
Barrier width $: w_{b}[\mathrm{~mm}]$ & 3 & 4 & 3 & 4 \\
Current angle $\left[{ }^{\circ}\right.$ elec $]$ & 0 & 40 & 0 & 40 \\
Current density $\left[\mathrm{A} / \mathrm{mm}^{2}\right]$ & 4 & 7 & 4 & 7 \\
Exterior radius $R_{\text {ext }}[\mathrm{mm}]$ & 135 & 135 & 120 & 150 \\
\hline
\end{tabular}

\section{B. Optimization method and results}

The previously defined optimization problem includes non-linear objective functions and a complex coupling between different domains of physics. Besides, a multiple set of solutions known as Pareto-optimal solutions is researched. Thus, in order to solve this constrained multi-objective problem, the NSGA-II algorithm is used [25].

The two optimization procedures are performed for a population of 400 individuals and 200 generations. The results lead to a tradeoff between the objectives and are represented by two Pareto fronts in Fig. 26.

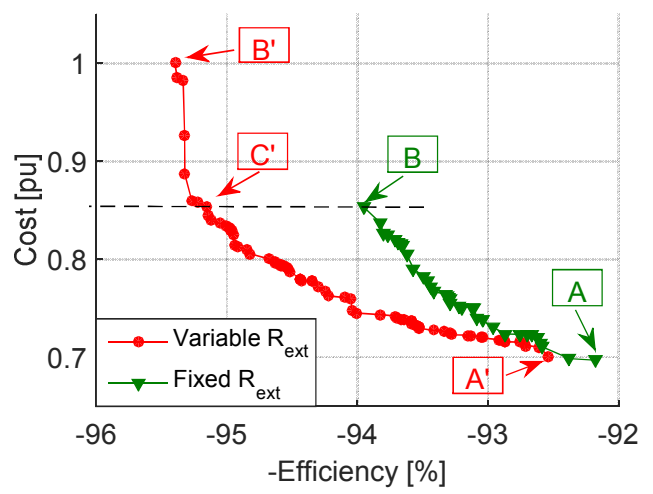

Fig. 26. Pareto fronts as a result of the optimization problem

The two ends of the Pareto fronts are denoted by A and B for the fixed $R_{\text {ext }}$ (green curve) and $\mathrm{A}^{\prime}$ and $\mathrm{B}^{\prime}$ for the variable $R_{\text {ext }}$ (red curve). The main performances of these machines are given in TABLE VIII and their designs are shown in Fig. 27.

Machines $\mathrm{A}$ and $\mathrm{A}^{\prime}$ deliver the same torque and power factor and have almost the same cost and efficiency. However, $\mathrm{A}^{\prime}$ needs less current compared to $\mathrm{A}$ and has a higher number of turns which increases the voltage $U_{r m s}$. The current and voltage values are key parameters for the motor drive design.

At fixed $R_{\text {ext }}$, the two ends of the Pareto front are made of machines having costs equal to $0.695 \mathrm{pu}$ (per unit) and 0.851 pu. Thus, a cost reduction of about $20 \%$ can be achieved between the extremum points of the Pareto front.

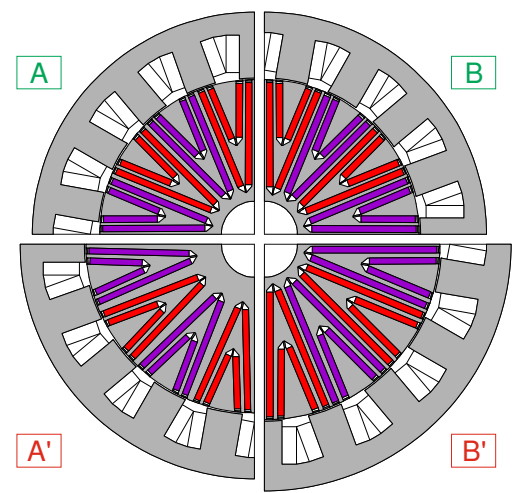

Fig. 27. Designs of the machines at the end of the Pareto fronts

TABLE VIII

PERFORMANCES OF THE MACHINES AT THE END OF THE PARETO FRONTS

\begin{tabular}{cccccccc}
\hline \hline Machine & $\begin{array}{c}T_{a v g} \\
{[N m]}\end{array}$ & $P F$ & $\begin{array}{c}U_{r m s} \\
{[V]}\end{array}$ & $\begin{array}{c}\eta \\
{[\%]}\end{array}$ & $\begin{array}{c}\text { Cost } \\
{[p u]}\end{array}$ & $\begin{array}{c}I_{r m s} \\
{[A]}\end{array}$ & $N_{s}$ \\
\hline $\mathrm{A}$ & 210.6 & 0.86 & 287 & 92.17 & 0.695 & 28 & 21 \\
$\mathrm{~B}$ & 211 & 0.93 & 347 & 93.95 & 0.851 & 21 & 22 \\
$\mathrm{~A}^{\prime}$ & 210.6 & 0.85 & 337 & 92.54 & 0.7 & 24 & 23 \\
$\mathrm{~B}^{\prime}$ & 220 & 0.92 & 309 & 95.15 & 1 & 25 & 20 \\
\hline
\end{tabular}

Another important analysis is done at fixed cost. Both machines $B$ and $C^{\prime}$ have a cost of $0.851 \mathrm{pu}$. Their characteristics are given in TABLE IX. They show that $\mathrm{C}^{\prime}$ compensate for its high $R_{\text {ext }}$ by minimizing $L_{s t k}$. Besides, at similar iron losses, the Joule losses of machine $\mathrm{C}^{\prime}$ are lower than those of machine B. Hence, at fixed cost, the efficiency can be improved by $1.2 \%$ when increasing the exterior radius of the motor.

TABLE IX

CHARACTERISTICS OF TWO MACHINES AT FIXED COST

\begin{tabular}{ccccccc}
\hline \hline \multirow{2}{*}{ Machine } & $\begin{array}{c}R_{\text {ext }} \\
{[\mathrm{mm}]}\end{array}$ & $\begin{array}{c}L_{\text {stk }} \\
{[\mathrm{mm}]}\end{array}$ & $\begin{array}{c}P_{i l} \\
{[\mathrm{~W}]}\end{array}$ & $\begin{array}{c}P_{\mathrm{Cu}} \\
{[\mathrm{W}]}\end{array}$ & $\begin{array}{c}\eta \\
{[\%]}\end{array}$ & $\begin{array}{c}\text { Cost } \\
{[\mathrm{pu}]}\end{array}$ \\
\hline $\mathrm{B}$ & 135 & 248 & 164.13 & 535.4 & 93.95 & 0.851 \\
$\mathrm{C}^{\prime}$ & 149 & 203 & 165.6 & 408 & 95.15 & 0.851 \\
\hline
\end{tabular}

\section{CONCLUSION}

This paper presented a multi-physics analytical model of a doubly salient V-shape IPM with concentrated winding. The developed magnetic model provides the flux distribution in the motor parts and takes into account the tangential leakage flux and the local saturation near the iron bridges. Its results have been compared to a finite element model and showed a very good agreement while being 5 times faster. The results of the iron loss model have been validated using a finite element analysis and were added to the electric circuit by the mean of a parallel resistance. A proposed model for the concentrated end-winding has been included in the thermal circuit. The results of the thermal model were compared to a MotorCad ${ }^{\circledR}$ design and also showed a good accuracy. Finally, a mechanical model has been introduced in order to compute the 
safety factors for breakdown and fatigue.

The multi-physics coupling has been achieved using the inputs and the outputs of the different models. A prototype has been built and the analytical coupled model has been validated using experimental tests.

Two bi-objective optimization problems have been defined and solved using NSGA-II. The results showed a possibility of reducing the cost by $20 \%$ between the extremum points of the Pareto front for a fixed exterior radius. Besides, if the exterior radius is increased, the efficiency of the motor could be improved by $1.2 \%$ without increasing the cost.

\section{REFERENCES}

[1] N. Bianchi and S. Bolognani, "Interior PM synchronous motor for high performance applications," in Proceedings of the Power Conversion Conference, 2002, vol. 1, pp. 148-153.

[2] E. Dlala, M. Solveson, S. Stanton, Z. Tang, M. Christini, R. Ong, and B. Peaslee, "Efficiency map simulations for an interior PM motor with experimental comparison and investigation of magnet size reduction," in IEEE International Electric Machines Drives Conference (IEMDC), 2013, pp. 23-29.

[3] T. Raminosoa, D. A. Torrey, A. El-Refaie, D. Pan, S. Grubic, and K. Grace, "Robust non-permanent magnet motors for vehicle propulsion," in IEEE International Electric Machines Drives Conference (IEMDC), 2015, pp. 496-502.

[4] A. Castagnini, A. Curci, and P. S. Termini, "Electromechanical tradeoff analysis of PM-assisted Synchronous reluctance motors," in 2015 IEEE International Electric Machines Drives Conference (IEMDC), 2015, pp. 287-292.

[5] E. E. Montalvo-Ortiz, S. N. Foster, J. G. Cintron-Rivera, and E. G. Strangas, "Comparison between a spoke-type PMSM and a PMASynRM using ferrite magnets," in IEEE International Electric Machines Drives Conference (IEMDC), 2013, pp. 1080-1087.

[6] P. Akiki, M. H. Hassan, J. C. Vannier, M. Bensetti, B. Dagusé, and M. McClelland, "Performance comparison of a doubly-salient motor with multi-V-shape ferrite magnets," in International Symposium on Power Electronics, Electrical Drives, Automation and Motion (SPEEDAM), 2016, pp. 205-212.

[7] Z. Djelloul-Khedda, K. Boughrara, F. Dubas, and R. Ibtiouen, "Nonlinear Analytical Prediction of Magnetic Field and Electromagnetic Performances in Switched Reluctance Machines," IEEE Transactions on Magnetics, vol. 53, no. 7, pp. 1-11, Jul. 2017.

[8] W. Jara, I. Petrov, J. Tapia, P. Lindh, and J. Pyrhönen, "Analytical model of tooth-coil winding permanent magnet synchronous machines with modular U-Shape stator," in 2016 XXII International Conference on Electrical Machines (ICEM), 2016, pp. 145-151.

[9] P. Liang, F. Chai, L. Chen, and Y. Wang, "Analytical Prediction of No-Load Stator Iron Losses in Spoke-Type Permanent Magnet Synchronous Machines," IEEE Transactions on Energy Conversion, vol. PP, no. 99, pp. 1-1, 2017.

[10] A. L. Rodríguez, D. J. Gómez, I. Villar, A. López-de-Heredia, and I. Etxeberria-Otadui, "Improved analytical multiphysical modeling of a surface PMSM," in 2014 International Conference on Electrical Machines (ICEM), 2014, pp. 1224-1230.

[11] M. T. B. Tarek and S. Choi, "Center post and rib length optimization of a high speed permanent magnet assisted synchronous reluctance motor," in 2017 IEEE International Electric Machines and Drives Conference (IEMDC), 2017, pp. 1-6.

[12] K.-D. Lee, M.-J. Kim, J.-H. Han, T.-C. Jeong, C.-S. Jin, W.-H. Kim, and J. Lee, "Design to reduce the cost and to improve the mechanical durability of IPMSM for the traction motor of military truck," in 2012 IEEE Vehicle Power and Propulsion Conference, 2012, pp. 154-159.

[13] Z. Han, H. Yang, and Y. Chen, "Investigation of the rotor mechanical stresses of various interior permanent magnet motors," in 2009 International Conference on Electrical Machines and Systems, 2009, pp. 1-6.

[14] P. Akiki, M. H. Hassan, J. C. Vannier, M. Bensetti, B. Dagusé, D. Prieto, and M. McClelland, "Non-linear analytical model for a multiv-shape IPM with concentrated winding," in 2016 XXII International Conference on Electrical Machines (ICEM), 2016, pp. 479-485.
[15] N. Bianchi and L. Alberti, "MMF Harmonics Effect on the Embedded FE Analytical Computation of PM Motors," IEEE Transactions on Industry Applications, vol. 46, no. 2, pp. 812-820, Mar. 2010.

[16] D. C. Hanselman, Brushless Permanent Magnet Motor Design. Writers' Collective, 2003.

[17] I. Petrov and J. Pyrhonen, "Performance of Low-Cost Permanent Magnet Material in PM Synchronous Machines," IEEE Trans. on Industrial Electronics, vol. 60, no. 6, pp. 2131-2138, Jun. 2013.

[18] X. Jannot, J. C. Vannier, C. Marchand, M. Gabsi, J. Saint-Michel, and D. Sadarnac, "Multiphysic Modeling of a High-Speed Interior Permanent-Magnet Synchronous Machine for a Multiobjective Optimal Design," IEEE Trans. on Energy Conversion, vol. 26, no. 2, pp. 457-467, Jun. 2011.

[19] P. H. Mellor, D. Roberts, and D. R. Turner, "Lumped parameter thermal model for electrical machines of TEFC design," IEE Proceedings B - Electric Power Applications, vol. 138, no. 5, pp. 205218, Sep. 1991.

[20] L. Idoughi, X. Mininger, F. Bouillault, L. Bernard, and E. Hoang, "Thermal Model With Winding Homogenization and FIT Discretization for Stator Slot," IEEE Transactions on Magnetics, vol. 47, no. 12, pp. 4822-4826, Dec. 2011.

[21] J. F. Trigeol, Y. Bertin, and P. Lagonotte, "Thermal modeling of an induction machine through the association of two numerical approaches," IEEE Transactions on Energy Conversion, vol. 21, no. 2, pp. 314-323, Jun. 2006.

[22] S. Kœchlin, "FKM Guideline: Strengths, Limitations and Experimental Validation," Procedia Engineering, vol. 133, pp. 309319, Jan. 2015.

[23] W. Beitz, Dubbel: Taschenbuch für den Maschinenbau. Springer 2001.

[24] T. H. Akinaga, T. Staudt, P. E. da Silva, and A. A. Espindola, "FEAbased method for estimating PM demagnetization in electrical motor design: Development and experimental validation," in 2016 XXII International Conference on Electrical Machines (ICEM), 2016, pp. 1749-1755.

[25] K. Deb, A. Pratap, S. Agarwal, and T. Meyarivan, "A fast and elitist multiobjective genetic algorithm: NSGA-II," IEEE Transactions on Evolutionary Computation, vol. 6, no. 2, pp. 182-197, Apr. 2002.

\section{BIOGRAPHIES}

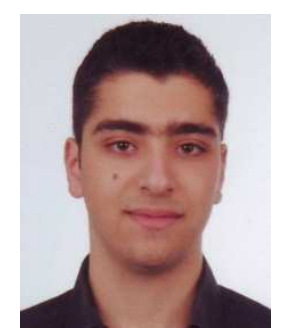

Paul Akiki received his Engineering degree and Master's degree from Ecole Supérieure d'Electricité (Supélec), France, in 2014.

$\mathrm{He}$ is currently working towards the Ph.D degree in Electrical Engineering with the Group of electrical engineering - Paris (GeePs) at CentraleSupelec, France. His current research interests include design and optimization of permanent magnet machines.

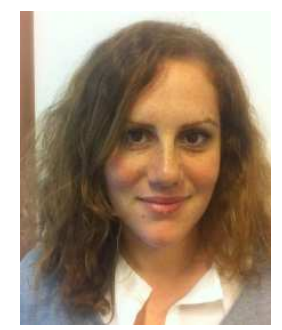

Maya Hage Hassan received her B.S. degree in mechanical engineering from the LU-Faculty of engineering, Lebanon, and her M.S. degree from the Ecole Centrale de Nantes, France, and a Ph.D. degree in electrical engineering from University Paris-Sud in 2014. She is now an Assistant Professor at CentraleSupélec and with the Group of electrical engineering - Paris. Her current research interests include optimization and design of electric machines and drives.

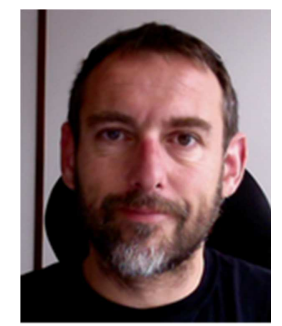

Philippe Dessante studied applied mathematics and physics at Montpellier and Versailles Universities, France, and received the Ph.D. degree from Laboratoire de Physique des Gaz et des Plasmas, Paris Sud University, France, in 2000. He is currently an Associate Professor at CentraleSupélec, France. His current research interests include the simulation and optimization of electro-technical systems 


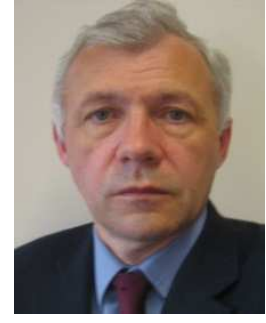

Jean-Claude Vannier received the degree in electrical engineering from Supélec, France, in1978, and the HDR (Accreditation to Supervise Research)degree from the Université of Paris-Sud, France, in 2006.He is a Professor and head of "Department of Energy and Power Systems" at CentraleSupelec, France. His primary research interest is in energy conversion systems (motors, actuators, generators) and concerns the modeling, the design, and the optimization of this equipment.

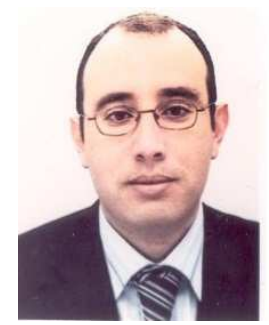

Mohamed Bensetti received his Master's degree (DEA) in 2001 and his Ph.D. in Electrical Engineering in 2004 from the University of ParisSud, France.He is now an Associate Professor at CentraleSupelec and a researcher with GeePs (Group of electrical engineering -Paris). His current research interests are Electromagnetic modeling, ElectroMagnetic Compatibility (EMC) and Power Electronics, including modelling, simulation and instrumentation.

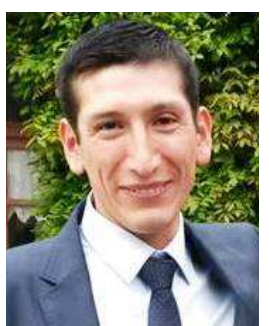

Dany Prieto received the M.S. degree in Electrical Engineering from the University of Nantes, France, in 2011 and the Ph.D. degree from CentraleSupelec in 2015.

Since 2015, he has been working with Leroy-Somer Motors as R\&D Electrical Engineer. His research interests include PMSM and induction motors with their power electronic supply.

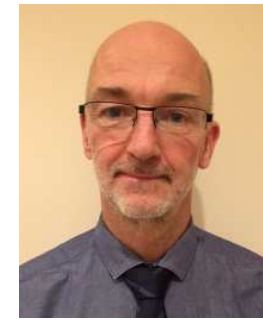

Mike McClelland obtained his engineering degree from Leeds University in 1985 and $\mathrm{PhD}$ in 1994.He has been working for Emerson ever since on the electromagnetic, mechanical and thermal design of brushless machines and is now employed as Technical Director for Leroy Somer Motors \& Drives division. He is a Fellow of the Institute of Engineering and Technology (UK). 